\title{
Some characteristics of Australian Aboriginal sign languages with hints for further questions for exploration
}

\author{
Adam Kendon \\ Institute for Research in Cognitive Science \\ University of Pennsylvania \\ adamk@dca.net
}

Keywords: Australian aborigines; alternate sign language; social interaction; spoken language

\section{Introduction}

When Europeans first began to venture from the coastal areas of what is today New South Wales and travel inland to areas of Australia beyond the Murray River Basin, it was noted, from time to time, the Aborigines encountered appeared to be using hand movements or "signs" as a means of communication. Probably the earliest report, published in 1874, is by Samuel Gason from South Australia. He noted the Dieri (as the local people were then known) made use of what appeared to be a complex sign language, which, he suggested, may have been connected to speech taboo practices associated with mourning. He claimed to have a thorough knowledge of this sign language, declaring it could be used for conversing about anything. He did not try to describe it, however, maintaining that to do so was beyond the capacity of words (Gason 1874, p. 35). After Gason's publication, several other reports appeared. For example, Spencer and Gillen, in 1899, described how women among the Warumungu used very complex signing, when, in mourning the death of a husband (and also certain other categories of male relatives), the practice was to avoid speaking altogether, sometimes for very extended periods (Spencer \& Gillen 1899). In 1897, W.E. Roth published a detailed description of the use of signs in his monograph on the aborigines of Northwest Central Queensland (Roth, 1897). The many signs Roth described were (almost certainly) explained to him by men, and it was the use of signs as a means of communicating over distances that first brought this signing to his attention.

These sign languages are not related to deafness, but were developed by speaker-hearers evidently to serve as a means of communication for use in circumstances when to use speech would either be impractical or inconvenient, or when, for ritual reasons it was forbidden. I have referred to them as alternate sign languages, to distinguish them from primary sign languages, which develop in communities of deaf persons, or in communities which contain a high proportion of deaf persons. Here the signing is developed by people who have no access or very limited access to spoken language. Alternate sign languages have been described for some societies other than those of Australia. Those used by the North American Indians are quite well known (see Mallery 1972 [1881] and Davis 2010). There are several reports of sign use among hunter-gatherers in southern Africa (Mohr \& Fehn 2012) and also from the forest-dwelling Pygmies of the Congo (Lewis 2009), as well as hunting societies from several other parts of the world (Divale and Zipin 1977). Certain European religious orders forbade speech in everyday life, and sign languages were developed in these communities. UmikerSebeok \& Sebeok (1987) provide a collection of accounts of such sign languages, which may be centuries old (see also Bruce 2007). Comparative discussions of these and other alternate sign languages may be found in Kendon (1988, Chapter 13) and Pfau (2012). 
A survey of the Australian reports from 1874 onwards into the middle years of the twentieth century, allowed me to propose (see Kendon 1988, Chapter 3 ) what appears to have been the pattern of sign language use throughout the continent before the presence of Europeans had had much impact on Aboriginal life. Sign languages were not reported from either the Eastern or the South Western coastal areas, they were not reported to be in use in southern New South Wales, Victoria, nor Tasmania. However, for the desert areas of South Australia, and northwards and westwards from there, there were enough reports of signing to suggest that it was in common use throughout these regions. This was also the case in the Cape York Peninsula and in northern and western Queensland. Reports of its use in the Kimberleys are scarce; it is only in Eastern Arnhem Land that we again encounter reports of its use (as we know from recent observation it is still in use there today). Signing was also reported to be in use in the Torres Straits islands (Haddon 1907).

\section{Factors governing the use of alternate sign languages in Aboriginal Australia.}

From my analysis of these records, it seemed the groups among whom signing was common and widespread were those in which speech taboos were often practised, either in association with male initiation rituals, or in association with mourning practices in which bereaved female relatives often refrained from using speech, sometimes for prolonged periods. However, although the distribution of both male and female speech taboos does correlate with the distribution of complex sign languages, it is also the case that signing has been reported from parts of Australia where speech taboos appear not to have been practised (as may well be the case in Arnhem Land) and it is also the case that signing can be widely used in many other circumstances, not just when speech taboos are being observed.

Accordingly, this raises the interesting question as to when signing might be used in everyday circumstances, as well as those governed by ritual observance. This is interesting in relation to much wider questions regarding the "communication economy" (Kendon 2004, p. 350) of a community: how are different communicative modalities, with their different properties and potentials, used in relation to one another? As my historical survey suggested, these sign languages have probably been in use among many groups in Australia for a very long time indeed. In the Aboriginal societies where this practice has been reported, members of these communities, both men and women, may often be able to choose to use sign or not. So an important question is: when and why are these sign languages used, and what are the factors that contribute to their elaboration? Speech taboos, as already noted, are one very important factor, but other features of Aboriginal sociality and ecology are also very important.

In the last Chapter of my 1988 book (Kendon 1988, Chapter 14), I discussed this issue at some length. Here I explored the idea the properties of signing as a communicative modality allow for modes of communication that are well suited to certain forms of interaction that are valued in Aboriginal society. For example, it can be used more discreetly than speech, making private exchanges possible in the otherwise quite public circumstances of every day Aboriginal life. It can serve as a useful mode of communication between people who are too far from one another for normal talk. If you can sign rather than shout, your interaction does not impose itself on everyone within earshot. Since signs can be varied in the explicitness of their performance, it is a useful medium for tentative communication, something highly valued in Aboriginal society in which interpersonal relations are under continual negotiation. Signing may have a less personal, more objective or neutral character, suitable for saying things in a more anonymous manner, something which is also valued in Aboriginal everyday life. And this feature of signing, also, may account for why it serves the wives of deceased husbands. Using sign may be a way of being less "present" in a social situation. Although allowing participation, at the same time, it allows the maintenance of a certain degree of distance or withdrawal. 
If it is still possible, these ideas would well repay further exploration, although to do this will require a kind of ethnographic study that concerns itself with the organisation of everyday communication conduct (rather in the spirit of the kind inquiry Erving Goffman initiated - see, for example, Goffman 1963) and which is alert to all of the several different communicative modalities used and how these are differentially employed in different circumstances.

\section{Relationships with spoken language}

Another very interesting issue regarding the sign languages of Aboriginal Australia has to do with their relationship to spoken language. As already mentioned, every indication suggests that these sign languages have been developed by speakers as alternatives to speaking - this is why I have termed these alternate sign languages, distinguishing them from primary sign languages, as these develop within communities of deaf, or in communities, or even just within families, where there is a relatively high proportion of deaf persons. In such circumstances, signing may be employed as a means of communication between hearing and deaf, as well as within communities of deaf persons. Primary sign languages differ from alternate sign languages insofar as they are developed by people who have no direct access to spoken language.

An important issue, then, in regard to alternate sign languages, such as those found in Aboriginal Australia, is the question of what relation, if any, they may have with the spoken languages in use in the community where such an alternate sign language has developed. This emerged as a major theme of my own investigations. These are reported in detail in four chapters of my 1988 book.

As I reported there, in their most elaborate form, as observed among older women among the Warlpiri (one of the language groups I worked with most extensively), these sign languages converge upon, or have a strong tendency to develop toward being a kind of kinesic (mainly manual) rendition of the units of meaning that are expressed by the semantic morphemes of the spoken language. Thus, many nouns are signed as renditions of the morphemic structure of the spoken word, rather than having a sign derived from a representation of some feature of the item in question. To illustrate, the word for "sun" in Warlpiri is wanta. The word for a species of red ant is wantawanta. In signing wanta, the hand, with just index and middle fingers extended and spread, and oriented with palm facing upwards, is lowered from an almost vertical position to a horizontal position in an action that might be derived from tracing the sun's trajectory in the sky. In signing wantawanta, the same hand shape and orientation as that used for wanta is employed, with a movement similar to that used in wanta. This, however, is now much abbreviated in amplitude and it is repeated. Thus, just as, in the spoken language, the word for "red ant" is a reduplication of the word for "sun", so in the sign language, the sign for "red ant" is a reduplication of the sign for "sun." There are many cases in which we find words that are compounded of two or more free morphemes are signed as compounds of the signs that are used for the component morphemes when these are used separately. Besides this, there are signs for suffixed forms (such as possessives), but tense and subject-object marking morphemes are not signed. This kind of relationship between the sign language and the spoken language is one of the reasons why the sign languages of different Aboriginal groups differ from one another. They also differ among themselves in many other ways, although the sign languages of adjacent groups tend to show some signs in common. In some domains, such as that of kinship, many signs seem to be similar in widely separated parts of Australia.

I also examined, with the help of expert older Warlpiri women signers, how narrative discourse was constructed. We compared the same narrative when signed or when spoken. Here, it appeared, the free re-combining of morpheme sequences in spoken Warlpiri that is 
so characteristic of that language, was observed in the signed versions. So, at least in the narrations of Winnie Nangala ${ }^{1}$ whether she spoke or signed in telling a story, she constructed her sentences in much the same way. This was confirmed when comparing shorter signed utterances with spoken utterances as observed in other older women signers (see Kendon 1988, Chapter 9).

All of this led me to conclude, at least among the Warlpiri (and also the Warumungu, a related group), these sign languages develop toward becoming a kinesic rendition of the semantic units that are provided by the semantic morphemes of the spoken language. I say develop toward, because in a survey I undertook to look at levels of knowledge of sign language among women of different ages at the Warlpiri settlement where I did most of my work (Yuendumu), I found the younger women, in their signing, showed much less spoken-morpheme to sign mapping (Kendon 1984).

Somewhat speculatively, I have suggested Warlpiri signing (as well as that of other North Central Desert groups, such as the Warlmanpa and the Warumungu) undergoes a kind of evolution toward being a kinesic rendition of the semantic categories supplied by the spoken language. In this way it recalls the development of writing. If one examines the history of writing, one finds it always starts out as a method of graphically representing concepts independently of how these might be represented in spoken language but then, over the course of its history, it converges more and more upon becoming something that can be interpreted as a rendition of what can be spoken. A similar process appears to be at work in an alternate sign language such as Warlpiri (Kendon 1988, p.432ff), although it is notable very few signs develop the reflective phonological features of speech.

A comparative survey of such alternate sign languages suggests this process of convergence toward a representation of concepts as these are rendered in spoken language does not always occur. Indeed, both the manner and extent of the relationship between an alternate sign language and spoken language varies. An alternate sign language such as that described by Barakat (1975) in use in a Cistercian monastery in the United States suggests an important influence on this sign language of English in its written form. In contrast, at least if we follow the analysis of Plains Indian Sign Language as undertaken by La Mont West (1960), this sign language has little to do with spoken language in its organisation.

Reviewing these various examples (see Kendon 1988, Chapter 13), at least three factors suggest themselves as governing whether and how an alternate sign language will converge in some respects upon the spoken language of its users. First of all, alternate systems that are restricted or specialised in their use, such as the kinesic codes used mainly in hunting (as among the hunter-gatherers - see, for example, Lewis 2009, Mohr and Fehn 2012) or, in industrial societies, in settings such as broadcast studios, stock exchanges, race tracks, factories, or in underwater settings (see Crystal and Craig 1978 for discussion of such systems), show very limited tendencies to relate to spoken language. Second, if the alternate sign language develops in communities where more than one spoken language is in use, as appears to have been the case with Plains Indian Sign Language which may have been used as a kind of lingua franca, it is not likely to show much convergence with any spoken language (West 1960, Davis 2010). I understand preliminary analyses of the sign language referred to as Yolnu Sign Language, as used in Arnhem Land, suggests it does not show much "mapping"

1. Winnie Nangala, Ruby Nangala Robertson and Judy Nampijimpa were my main Warlpiri consultants at Yuendumu, where I was also given indispensable help by Mary Laughren, a linguist at that time engaged on compiling a dictionary of Warlpiri. 
onto the spoken language, and in this it differs from the sign languages of the North Central Desert, such as Warlpiri (Bauer 2012). This may be because the communities where Yolnu sign language is used are multilingual, in a way that the North Central Desert communities are not. If this is so, this might explain, at least in part, why Yolnu Sign Language shows much less tendency to "map on" to a specific spoken language. Third, the morphological character of the spoken language in the community where an alternate sign language develops must also be considered when looking at how the alternate sign language may relate to it. Thus, a language such as Warlpiri, which is highly agglutinative with sentences being constructed from sequences of morphemes with very little inflexion, might seem to lend itself rather easily to a form of morpheme-by-morpheme representation in another modality. The languages of North America, on the other hand, in many cases represent the extreme of a so-called "fusional" morphology. Here, we would predict, even where an alternate sign language is developed in relation to just one of these languages, it would not show anything like the same sort of convergence toward spoken language representation observed in the Australian North Central Desert. According to such limited information we have on the relationship between these sign languages and the spoken languages used in the communities where they have been developed, this prediction appears to have been borne out (see West 1960).

An outstanding issue in the study of Australian Aboriginal sign languages that remains, thus, is of how these do relate to spoken languages: Is there variation in the nature of this relationship, and what factors govern this variation? If it were possible, we need more studies so we could compare, across Australia, how different alternate sign languages vary in how they are patterned in relation to the spoken languages and try to identify the different conditions that might be related to this. I think the issue of how different language codes, differing in modality, may relate or diverge from one another raises interesting theoretical issues about the relationship between "meaning units" and how these meaning units get represented in different modalities. There is, I suppose, a sort of reciprocal relationship between the modality employed in expression and the "meaning units" that get expressed. "Meaning units" indeed govern what gets expressed, but they are themselves governed by what a given modality makes possible for expression.

\section{Comparisons with primary sign languages}

Another question that needs much further exploration has to do with how these alternate sign languages compare structurally with primary sign languages. In my 1988 book, I reported very detailed analyses of sign formation, comparing this with what was then available on primary sign languages, mainly American Sign Language. Some general points that emerged from this were the North Central Desert (NCD) sign languages are overwhelmingly manual. Almost no use of facial actions was observed while signing. This seems to be consistent with its use as an alternate when observing a speech taboo. Movements of the mouth tend to be suppressed, when signing when speech is tabooed. It is interesting to observe, however, that women observing speech taboo often accompany their signing with a kind of "grunting" that seems to mark points of emphasis and to reflect variations in tone and pitch of the voice - as if prosody may be expressed audibly but not anything that involves oral articulation. In this, these sign languages are in marked contrast to primary sign languages.

With regard to the components of sign expression - sign location, sign actor (hand configuration and orientation), sign action - although one handed signs are very much in the majority, and although sign locations are employed that had not been reported for primary sign languages at that time, the principles of sign formation were otherwise found to be very similar to those reported for primary sign languages. I concluded my discussion of comparisons between alternate and primary sign languages with these words: 
"there are enough important similarities [between sign formation in NCD sign languages and American Sign Language] to allow us to maintain the (perhaps rather unsurprising) view that the principles governing sign formation in the NCD sign languages are the same as those found operating in any other sign language." (Kendon 1988, p. 158).

I then continued:

"Because of the mode of production of signs, and given the characteristics of both the anatomical structure and the visual perceptual systems of the producers, we may expect all sign languages to display certain features in common. The results of the analyses of the formational characteristics of the NCD sign languages seem to be consistent with this position." (Kendon 1988, p. 158).

I followed this analysis of sign formation with a study of the relationship between sign form and sign meaning (Kendon 1988, Chapter 6). Principles of "iconicity", as worked out by Mark Mandel (1977) for American Sign Language, and which I had further explored in relation to a primary sign language I had worked on in Papua New Guinea (Kendon 1980, Part II), were further explored in relation to mainly Warlpiri signing. In general, it was concluded the same principles by which iconic expression manifests itself in signing, as explored by Mandel and myself in respect to other sign languages, were also in operation with Warlpiri sign language. It is notable, however, that a very large number of Warlpiri signs defy any sort of "iconic" derivation. I suggested this is evidence for the antiquity of this sign language. Nevertheless, we can detect processes that transform imagistic representations into formations governed by system-wide sign formation processes (so-called "phonological" processes) in Warlpiri sign language, just as we may find them in all other sign languages that have been examined so far, whether primary or alternate.

Warlpiri and other NCD sign languages do make limited use of face and gaze orientation, deictic (pointing) processes and the establishment of virtual spaces as referential devices in ways very similar to what has been observed in primary sign languages. However, according to my observation, nothing in these sign languages that seemed to resemble the so-called "classifiers" that are found in primary sign languages (Emmorey 2003), were found in either Warlpiri or Waramungu sign languages, the NCD sign languages where I was able to obtain signed narratives (where you might expect to see "classifiers" in use). This lack of classifier use may well be related to the tendency for these sign languages to be tied to spoken language. They tend not to exploit, very much, the spatial-expressive potentialities of the kinesic medium as is found so extensively in primary sign languages, and also, according to La Mont West (1960), in Plains Indian Sign Language. According to him, this sign language functions as a system more or less independent of spoken language, and makes extensive use of spatial relationships for grammatical purposes.

Comparative studies of different Australian Aboriginal sign languages remains much needed. I did include a comparative study of five different NCD sign languages, mainly from a lexical point of view (see Kendon 1988, Chapters 11 \& 12), but much more should be done. And comparisons with primary sign languages - and today we have a wealth of knowledge of them that was not available in 1988 - would also be very valuable.

\section{Deafness and alternate sign languages in Aboriginal Australia.}

The final issue I would like to comment on is the question of whether and how, and to what extent, deaf Aboriginal persons make use of these sign languages. In my own experience 
in the field at Yuendumu and elsewhere in the North Central Desert, I encountered but two deaf individuals, and neither made any use at all of the local Aboriginal sign language. One communicated only by writing, the other had learned AUSLAN (Australian Sign Language) at an institution in Adelaide and combined this with expressions developed among members of his family. I had no opportunity to study his signing and cannot say whether, in his signing, he was influenced by the local alternate sign language. From what I was told by residents at Yuendumu, and elsewhere, it seemed to be the general opinion the local alternate sign language was not used by deaf persons, however I find it hard to believe deaf individuals in communities where there are alternate sign languages would not, in such signing, exhibit some influences from the alternate sign language.

In modern times, as a consequence of Aborigines being largely forced to live in large settlements, often in rather unhygienic conditions, quite unlike their traditional modes of life, there has been a spread of ear infections that create post-lingual deafness in children on quite a large scale (Bauer 2012). Where this is the case, it is an interesting question as to how and in what way such children make use of signs and the extent to which, in doing so, they borrow from any alternate sign language that may be locally present. It seems clear, however, that Australian Aboriginal sign languages were fashioned by hearing people as part of a complex development of communication strategies developed in relation to ritual and other communicative needs of everyday life and, in the first instance, in any case, had nothing to do with deafness.

\section{A concluding reflection}

Alternate sign languages have not attracted much attention from sign language researchers no reference is made to them in the otherwise comprehensive survey of sign languages edited by Diane Brentari (2010), for example. This may be because students of sign language, have been put off by the fact they were seen to have a direct relationship with spoken language, or were even, perhaps, in some way derived from them and would thus not be regarded as "pure sign languages". Indeed, my own work on the Australian North Central Desert Languages shows they can be strongly influenced by the spoken languages of their users. However, it is my view it is just this relationship with spoken language that gives these sign languages a special interest. It raises many questions about the relationship between modality of expression, the semiotic properties of different modalities, and how these are interrelated in the course of their use in everyday life, where more than one modality of linguistic expression, each with its own properties, is simultaneously available for use in interaction. The issue of how these modalities influence one another, when systems in parallel are fashioned in the way that appears to have happened in Australian Aboriginal communities, would seem to be one of particular fascination, especially in these days, when "multimodality" is all the rage.

\section{References}

Barakat, R.A. (1975). Cistercian Sign Language. Kalamazoo, MI: Cistercian Publications.

Bauer, A. (2012). The use of signing space in a shared sign language of Australia. Inaugural Dissertation. Department of Linguistics, Cologne University.

Brentari, D. (Ed.). (2010). Sign Languages. Cambridge: Cambridge University Press.

Bruce, S.G. (2007). Silence and Sign Language in Medieval Monasticism: The Cluniac Tradition c.900-1200. Cambridge: Cambridge University Press. 
Crystal, D. \& Craig, E. (1978). Contrived sign languages. In I.M. Schelsiger \& L. Namir (Eds.), Sign Language of the Deaf: Psychological, Linguistic and Sociological Perspectives (pp. 141-168). New York, USA: Academic Press.

Davis, J.E. (2010). Hand Talk: Sign Language Among American Indian Nations. Cambridge: Cambridge University Press.

Divale, W.T. \& Zipin, C. (1977). Hunting and the development of sign language: a cross-cultural test. Journal of Anthropological Research, 33, 185-201.

Emmorey, K. (Ed.) (2003). Perspectives on Classifier Constructions in Sign Languages. Mahwah, New Jersey: Lawrence Erlbaum.

Gason, S. (1874). The Dieyerie Tribe of Australian Aborigines. Adelaide: W.W.Cox. Government Printer.

Haddon, A.C. (1907). Reports of the Cambridge Anthropological Expedition to the Torres Straits. Volume III Linguistics, S. H. Ray (Ed.). Cambridge: Cambridge University Press.

Goffman, E. (1963). Behavior in Public Places. New York: The Free Press of Glencoe.

Kendon, A. (1980). A Description of a Deaf-Mute Sign Language, Etc. Part II: Aspects of Utterance Construction. Semiotica, 32, 245-313.

Kendon, A. (1984). Knowledge of sign language in an Australian Aboriginal community. Journal of Anthropological Research, 40, 556-576

Kendon, A. (1988) [re-issued 2013]. Sign Languages of Aboriginal Australia: Cultural, Semiotic and Communicative Perspectives. Cambridge: Cambridge University Press.

Kendon, A. (2004). Gesture: Visible Action as Utterance. Cambridge: Cambridge University Press.

Lewis, J. (2009). As Well as Words: Congo Pygmy Hunting, Mimicry and Play. In R. Botha \& C. Knight (Eds.), The Cradle of Language (pp. 236-256). Oxford: Oxford University Press.

Mallery, G. (1972 [1881]) Sign Language among North American Indians Compared with that among Other Peoples and Deaf Mutes. The Hague: Mouton de Gruyter.

Mandel, M. (1977). Iconic Devices in American Sign Language. In L.A. Friedman (Ed.), On the Other Hand: New Perspectives on American Sign Language (pp. 57-107). New York: Academic Press.

Mohr, S. \& Fehn, A-M. (2012). Phonology of hunting signs in two Kalahari Khoe-speaking groups. (Ts'ixa and ||Ani). LSA Annual Meeting 2013, Extended Abstracts. Retrieved from http://www.linguisticsociety.org/content/lsa-2013-annual-meeting-extended-abstracts.

Pfau, R. (2012). Manual communication systems: Evolution and variation. In R. Pfau, M. Steinbach \& B. Woll (Eds.), Sign Language: An International Handbook (pp. 513-551). Berlin: Mouton de Gruyter.

Roth, W.E. (1897). Ethnological Studies Among the North-West-Central Queensland Aborigines. Brisbane: Edmund Gregory, Government Printer.

Spencer, B. \& Gillen, F.J. (1899). The Native Tribes of Central Australia. London: Macmillan Co.

Umiker-Sebeok, J. \& Sebeok, T.A. (Eds.). (1987). Monastic Sign Languages. Berlin: Mouton de Gruyter.

West, L.M. (1960). The Sign Language: An Analysis. Volume I. Volume II: Dialects. Unpublished Doctoral Dissertation, Department of Linguistics, Indiana University, Bloomington, Indiana 